\title{
Social Adversity, Sleep Characteristics, and Elevated Blood Pressure Among Young Adult Black Females
}

\author{
Jewel Scott, ${ }^{1, *}$ Susan Silva, ${ }^{1}$ and Leigh Ann Simmons ${ }^{2}$
}

\begin{abstract}
Purpose: We examined whether sleep characteristics and adverse social exposures were associated with elevated blood pressure (BP) in young adult black women.

Methods: This is a cross-sectional analysis of existing data from 581 black females who participated in the National Longitudinal Study of Adolescent to Adult Health (Add Health). Adverse social exposures included child abuse, discrimination, perceived stress, social isolation, and subjective social status. Self-reported sleep characteristics were measures of duration, latency, continuity, and snoring. Logistic regression was used to evaluate the influence of social exposures and sleep characteristics on BP.

Results: Among the women (mean age $=29.1$ years), 32.4\% had elevated BP ( $\geq 130$ systolic or $\geq 80$ diastolic). In adjusted analysis, poor sleep continuity (adjusted odds ratio $[\mathrm{aOR}]=1.70,95 \%$ confidence interval $[\mathrm{Cl}]=1.07-$ 2.70) and discrimination $(\mathrm{aOR}=1.61,95 \% \mathrm{Cl}=1.00-2.58)$ were associated with higher odds of elevated $\mathrm{BP}$, while more social isolation $(\mathrm{aOR}=0.69,95 \% \mathrm{Cl}=0.48-0.99)$ was associated with lower odds of elevated $\mathrm{BP}$.

Conclusion: Poor sleep continuity and experiencing discrimination may represent key risk factors for hypertension in young black females. Unexpectedly, being more isolated was associated with lower BP. Future research should examine how to adapt current paradigms and measures of social connectedness, isolation, and stress to better elucidate the impact of these factors on the long-term health of young black females.
\end{abstract}

Keywords: sleep; hypertension; discrimination; health disparities; young adulthood; stress

\section{Introduction}

Hypertension is among the top three leading contributors to death and disability worldwide, ${ }^{1}$ and black females are among the most affected. In the United States, the overall prevalence of hypertension is $29 \%$, but among black females, the prevalence is $40 \%$ $\left(\right.$ Ref. $\left.^{2}\right)$. Elevated blood pressure (BP) develops at younger ages in black females compared to women of other ethnicities. ${ }^{1,3}$ More attention to risk factors that contribute to elevated BP in black women younger than 40 years is needed.

Known risk factors for elevated BP, such as obesity and family history, do not fully explain the disparity in elevated BP prevalence, especially among young black females. ${ }^{4,5}$ Mounting evidence suggests that adverse social exposures, including child abuse, ${ }^{5,6}$ social isolation, ${ }^{7,8}$ discrimination, ${ }^{9-11}$ and socioeconomic disadvantage, ${ }^{11-13}$ have a negative impact on physical health. For example, in a nationally representative study of over 16,000 individuals, social isolation was identified as a risk factor for mortality with effects on par with tobacco use and BP. ${ }^{8}$ Owing to the social stratification of society, discrimination is a social adversity that many black women experience. ${ }^{10,11,14}$ In the Jackson Heart Study, a prospective, cohort study of black Americans, women were more likely to report discrimination as being very stressful, and the burden of discrimination was associated with high BP. ${ }^{14}$ Current

\footnotetext{
${ }^{1}$ Duke University School of Nursing, Durham, North Carolina, USA.
}

${ }^{2}$ Department of Human Ecology, University of California, Davis, Davis, California, USA.

*Address correspondence to: Jewel Scott, PhD, MSN, FNP-C, Duke University School of Nursing, Durham, 309 Trent Drive, NC 27710, USA, E-mail: jewel.scott@duke.edu

(c) Jewel Scott et al., 2020; Published by Mary Ann Liebert, Inc. This Open Access article is distributed under the terms of the Creative Commons License (http://creativecommons.org/licenses/by/4.0), which permits unrestricted use, distribution, and reproduction in any medium, provided the original work is properly cited. 
and early life experiences of adversity are potential contributors to adult cardiovascular health $(\mathrm{CVH})$. Exposure to multiple forms of childhood adversity, such as child abuse and parental mental illness, is associated with up to a fourfold increase in risk for cardiovascular disease (CVD) ${ }^{5,6}$ Despite these documented relationships, few studies have focused on these stressors exclusively in young black women.

Sleep as a health behavior is important, because a growing body of literature has identified a strong association between sleep and CVD. ${ }^{15}$ Insomnia (i.e., difficulty falling asleep or staying asleep) and short sleep duration are examples of sleep characteristics that elevate risk for hypertension, ${ }^{15}$ but have not been widely studied among young black women. Researchers using data from the National Longitudinal Youth Survey found a divergence in sleep duration between white and black young adults occurs around age 24 years, after which black young adults sleep less. ${ }^{16}$ Examining sleep behaviors during young adulthood could be critical for early identification of black women at risk for hypertension.

Comparative studies were instrumental in identifying inequities in $\mathrm{CVH}$ that exist between populations in the United States. However, now that CVH disparities are well established, within-group studies may permit a more contextualized study of social contributors to the development of $\mathrm{CVH}$ in black women as supported by critical race theory. ${ }^{17}$ Furthermore, the weathering hypothesis underscores the need to study whether adversities and health behaviors are associated with BP in young adult black women. ${ }^{18,19}$ Thus, the research question is, "Are multiple social adversities and sleep characteristics indicators of increased risk for elevated BP among young Black females?"

\section{Methods}

Design and sample

This study was a secondary analysis of data collected as part of The Longitudinal Adolescent to Adult Health Study (Add Health) ${ }^{20}$ and deemed exempt by the Institutional Review Board. A total of 20,745 students were enrolled at wave 1 in 1994, and followed prospectively with periodic, in-person data collection. The study has maintained an overall retention rate of $80.3 \%$. Data for this project were obtained from the Add Health fully de-identified, public use data, which is a random sampling of $50 \%$ of the total study population. The analysis sample comprised non-Hispanic, black females who participated in the 2006-2008 (wave 4) data collection when BP was assessed for the first time. Females who identified black as one of multiple racial identities were excluded because social experiences and health outcomes may be meaningfully different for multiracial females. ${ }^{21}$ Women who were pregnant were also excluded because physiological changes in pregnancy can result in altered $\mathrm{BP}^{22}$ The analysis included 581 women who met eligibility criteria (Fig. 1).

\section{Measures}

Outcome. The outcome was elevated BP, as defined by the 2017 American Heart Association (AHA) guidelines. Participants rested in a seated position for $5 \mathrm{~min}$ before three $\mathrm{BP}$ measurements were collected using the Microlife BP3MC1-PC-IB monitor (MicroLife USA, Dunedin, FL). ${ }^{23}$ The first reading was discarded and the average of the second and third measurements was recorded. Consistent with the most recent guidelines, systolic BP $\geq 130$ or a diastolic $\mathrm{BP} \geq 90$ was coded as elevated BP. Since BP is only measured once, we cannot determine hypertensive status, but as $\mathrm{BP}$ readings increase, cardiovascular $(\mathrm{CV})$ risk also increases. $^{1,24}$ Thus, a single BP reading can provide meaningful data about potential risk for early-onset CVD in a young adult population. Covariates included self-reported prior diagnosis of hypertension, diabetes, hyperlipidemia, and heart disease.

Demographic and clinical characteristics. Age, education, and annual income were self-reported. Height and weight were measured and overweight and obesity were determined by applying the AHA standardized cutoffs. ${ }^{1}$ Depression symptoms were measured using the 10-item Center for Epidemiologic Studies Scale, with scores of 10 or above representing clinically significant depressive symptoms. ${ }^{25,26}$ The weighted Cronbach's $\alpha$ in this sample was $\alpha=0.82$. Participants rated their overall health, and from this, a dichotomous measure (poorer health, defined as fair/poor health vs not poorer health, defined as good/very good/excellent) was created, consistent with other research of selfrated health. ${ }^{27}$

Sleep characteristics. The following four sleep characteristics were assessed at wave 4: (1) snoring, (2) sleep continuity, (3) sleep onset, and (4) sleep duration. The first three were assessed as dichotomous questions, whereas sleep duration was assessed based on selfreported bed and wake times on a typical work or school day. See Table 1 for definitions and coding. 


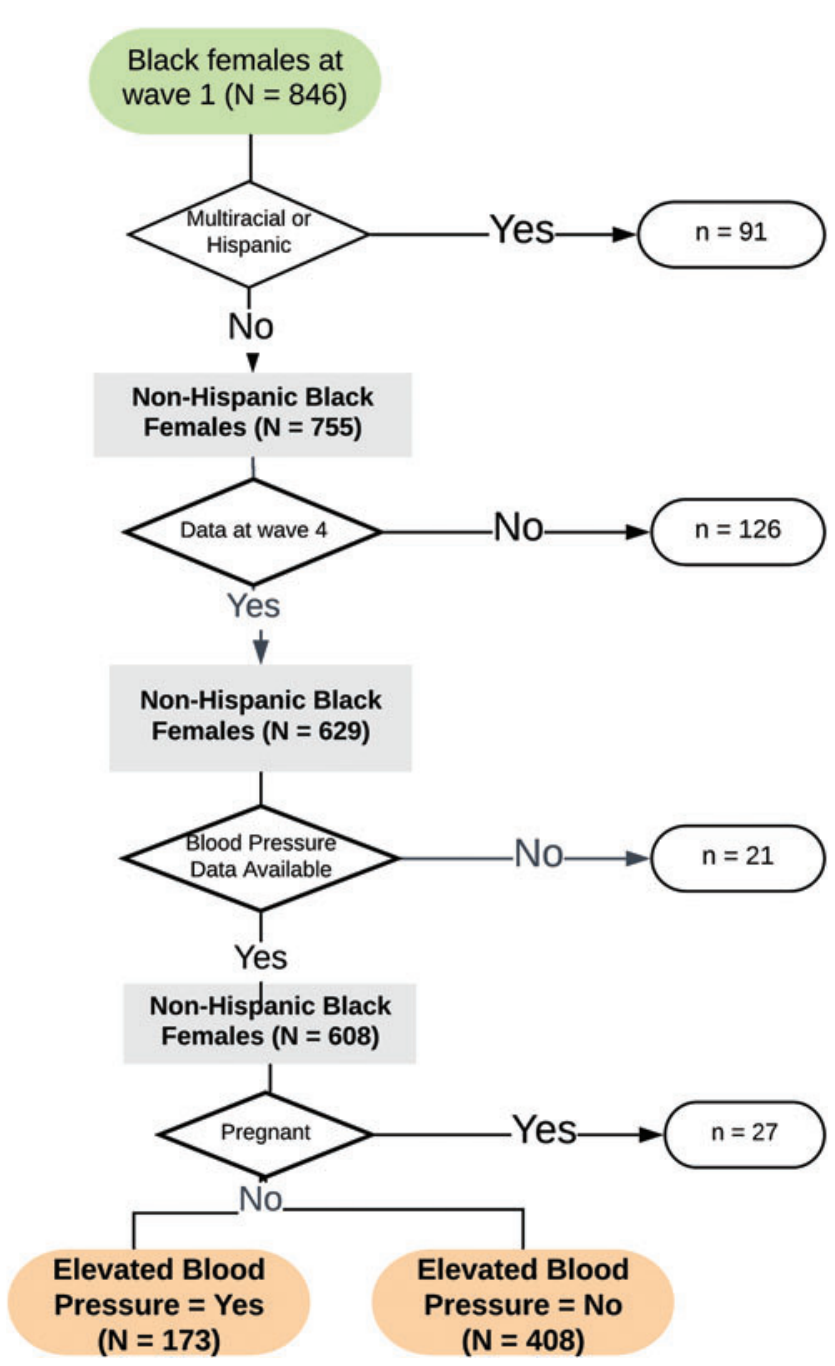

FIG. 1. Data available for analysis.

Adverse social exposures. Adverse exposures included the following: (1) discrimination, (2) subjective social status, (3) perceived stress, (4) social isolation, and (5) child abuse. Discrimination was measured as a single question from the Everyday Discrimination Scale, ${ }^{11}$ which asked "How often are you treated with less courtesy or respect than others?" Responses were dichotomized such that often or frequent were coded as yes. Subjective social status was assessed using the MacArthur scale, which is based on an ordinal, 10step scale where 10 represents people with the most money, education, and best respected jobs. ${ }^{12,13}$ Using a picture of a 10-step ladder, participants were asked to indicate their social position compared to other peo- ple in the United States. Perceived stress was measured using the 4 -item Perceived Stress Scale, ${ }^{28}$ and the weighted Cronbach's $\alpha$ in this sample was 0.64 . Both subjective social status and perceived stress were dichotomized based on their respective medians to facilitate a parsimonious analysis of these continuous variables. Social isolation was assessed as a dichotomous question, which asked "How often do you feel isolated from others?" Child abuse was assessed retrospectively at wave 4, using questions such as "before age 18 years, how often did a parent or caregiver hit you with a fist, or kick you?" Any physical, emotional, or sexual abuse constituted an adverse social exposure (yes/no). 
Table 1. Participant Characteristics $(N=581)$

\begin{tabular}{|c|c|c|c|c|}
\hline \multirow[b]{2}{*}{ Predictor } & \multirow[b]{2}{*}{ Description } & \multirow[b]{2}{*}{$n^{\mathrm{a}}$} & \multicolumn{2}{|c|}{ Weighted } \\
\hline & & & Mean or percent & SE \\
\hline \multicolumn{5}{|l|}{ Demographics } \\
\hline Age & Age in years & 581 & 29.09 & 0.22 \\
\hline Low education & Yes ( $\leq$ high school) & 116 & $25.91 \%$ & 3.40 \\
\hline Low income & $\begin{array}{l}\text { No (post-secondary) } \\
\text { Yes }(<20 \mathrm{~K})\end{array}$ & $\begin{array}{l}465 \\
140\end{array}$ & $\begin{array}{l}74.09 \% \\
31.51 \%\end{array}$ & $\begin{array}{l}3.40 \\
3.10\end{array}$ \\
\hline & No & 397 & $68.49 \%$ & 3.10 \\
\hline \multicolumn{5}{|l|}{ Clinical characteristics } \\
\hline Depression symptoms & $\begin{array}{l}\text { No } \\
\text { Yes (CESD } \geq 10)\end{array}$ & $\begin{array}{l}140 \\
147\end{array}$ & $\begin{array}{l}22.32 \% \\
26.51 \%\end{array}$ & $\begin{array}{l}1.87 \\
2.19\end{array}$ \\
\hline Poorer health & $\begin{array}{l}\text { No } \\
\text { Yes (self-rated fair, poor) }\end{array}$ & $\begin{array}{r}434 \\
82\end{array}$ & $\begin{array}{l}73.49 \% \\
15.06 \%\end{array}$ & $\begin{array}{l}2.19 \\
1.85\end{array}$ \\
\hline Health behaviors & No & 499 & $84.94 \%$ & 1.85 \\
\hline Tobacco use & Yes & 141 & $26.43 \%$ & 3.37 \\
\hline Poor diet & $\begin{array}{l}\text { No } \\
\text { Yes (fast food }>2 \text { days/week) }\end{array}$ & $\begin{array}{l}429 \\
237\end{array}$ & $\begin{array}{l}73.57 \% \\
42.06 \%\end{array}$ & $\begin{array}{l}3.37 \\
2.38\end{array}$ \\
\hline Physical inactivity & $\begin{array}{l}\text { No } \\
\text { Yes ( }<4 \text { days a week) }\end{array}$ & $\begin{array}{l}342 \\
491\end{array}$ & $\begin{array}{l}57.94 \% \\
86.72 \%\end{array}$ & $\begin{array}{l}2.38 \\
1.61\end{array}$ \\
\hline & No & 90 & $13.28 \%$ & 1.61 \\
\hline \multicolumn{3}{|l|}{ Sleep characteristics } & & \\
\hline Poor sleep continuity & $\begin{array}{l}\text { No } \\
\text { Yes (frequent awakening) }\end{array}$ & $\begin{array}{l}388 \\
229\end{array}$ & $\begin{array}{l}65.69 \% \\
40.03 \%\end{array}$ & $\begin{array}{l}2.19 \\
2.43\end{array}$ \\
\hline Snoring & $\begin{array}{l}\text { No } \\
\text { Yes (snore/stop breathing) }\end{array}$ & $\begin{array}{l}347 \\
283\end{array}$ & $\begin{array}{l}59.97 \% \\
51.43 \%\end{array}$ & $\begin{array}{l}2.43 \\
2.82\end{array}$ \\
\hline Short sleep duration & $\begin{array}{l}\text { No } \\
\text { Yes }(<6 h)\end{array}$ & $\begin{array}{r}291 \\
62\end{array}$ & $\begin{array}{l}48.57 \% \\
11.00 \%\end{array}$ & $\begin{array}{l}2.82 \\
1.57\end{array}$ \\
\hline Long sleep duration & $\begin{array}{l}\text { No } \\
\text { Yes }(>9 h)\end{array}$ & $\begin{array}{r}518 \\
54\end{array}$ & $\begin{array}{r}89.00 \% \\
9.56 \%\end{array}$ & $\begin{array}{l}1.57 \\
1.32\end{array}$ \\
\hline & No & 526 & $90.44 \%$ & 1.32 \\
\hline Adverse social exposures & & & & \\
\hline Social isolation & Yes & 339 & $57.49 \%$ & 3.33 \\
\hline Discrimination & $\begin{array}{l}\text { No } \\
\text { Yes }\end{array}$ & $\begin{array}{l}242 \\
171\end{array}$ & $\begin{array}{l}42.51 \% \\
31.13 \%\end{array}$ & $\begin{array}{l}3.33 \\
2.40\end{array}$ \\
\hline High perceived stress & $\begin{array}{l}\text { No } \\
\text { Yes (PSS-4 above 5) }\end{array}$ & $\begin{array}{l}410 \\
338\end{array}$ & $\begin{array}{l}68.87 \% \\
59.51 \%\end{array}$ & $\begin{array}{l}2.40 \\
3.45\end{array}$ \\
\hline Low subjective social status & $\begin{array}{l}\text { No } \\
\text { Yes }\end{array}$ & $\begin{array}{l}243 \\
402\end{array}$ & $\begin{array}{l}40.49 \% \\
71.16 \%\end{array}$ & $\begin{array}{l}3.45 \\
2.47\end{array}$ \\
\hline Child abuse & $\begin{array}{l}\text { No } \\
\text { Yes }\end{array}$ & $\begin{array}{l}176 \\
184\end{array}$ & $\begin{array}{l}28.84 \% \\
31.43 \%\end{array}$ & $\begin{array}{l}2.47 \\
1.98\end{array}$ \\
\hline & No & 382 & $68.57 \%$ & 1.98 \\
\hline Outcome: elevated BP & Yes $(B P \geq 130 / 90)$ & 173 & $32.38 \%$ & 2.60 \\
\hline & No & 408 & $67.62 \%$ & 2.60 \\
\hline
\end{tabular}

annweighted.

BMI, body mass index; BP, blood pressure; CESD, Center for Epidemiologic studies; PSS, perceived stress scale; SE, standard error.

Health behaviors. Participants were asked if they had used tobacco in the last 30 days, and any use was coded as yes. Diet was assessed by the question, "How many times did you eat fast food in the last 7 days?" Fast food intake of more than twice per week was coded as yes for unhealthy diet, based on other studies of dietary habits and $\mathrm{CVH}^{29}{ }^{29}$ Phys- ical activity was assessed with a series of questions about frequency of participation in a variety of activities (e.g., dance and aerobics) in the last 7 days. The activity frequencies were summed to represent activity level of participants. Fewer than four occurrences of activity in the last 7 days was coded as inactive. 


\section{Analytic strategy}

Data were analyzed using SAS version 9.4 (SAS Institute, Cary, NC). Sample weighting to account for the complex survey design was applied in all analyses to ensure representativeness of the survey data. Descriptive statistics were used to detail sample characteristics and analysis variables. Nondirectional statistical tests were conducted with significance set at 0.10 per test for bivariate analyses to select eligible covariates for the multivariable analysis, where significance was set at 0.05 . The significance level was not adjusted for multiple tests as the intent of this initial exploratory study was to inform the development of future hypothesis-driven research. ${ }^{30}$

Bivariate logistic regression was used to examine the relationship between each sleep characteristic and adverse social exposure with elevated BP. In addition, bivariate regression was applied to identify demographic and clinical characteristics, and health behaviors significantly associated with elevated BP. The latter characteristics were included as covariates in the subsequent multivariable regression model.

The initial multivariable logistic regression included sleep characteristics, and adverse social exposures as predictors of elevated BP (model 1). Model 2 adjusted for demographics, clinical characteristics, and health behaviors and model 3 adjusted for all of the above and past medical history. Odds ratios (ORs) from the bivariate models and adjusted odds ratios (aORs) from the multivariable models along with their 95\% confidence intervals (CIs) were used to address effect size and clinical relevance of results. The sample size of 581 provided at least $80 \%$ power for the initial and most complex multivariable model with potentially 20 predictors (demographic, clinical, health behavior, sleep, and adverse social exposures).

\section{Results}

\section{Participant characteristics}

Table 1 presents the characteristics of the 581 young adult black females, of whom 408 had normal BP (elevated $\mathrm{BP}=0$, no) and 173 women had elevated $\mathrm{BP}$ (elevated $\mathrm{BP}=1$, yes). The mean age was 29.1 years (range: $25-34$ years) with $32 \%$ with a low annual income. Clinically, $78 \%$ had overweight or obesity, $27 \%$ reported depressive symptoms, $15 \%$ rated their health as poor or fair, $26 \%$ used tobacco products, and $87 \%$ were physically inactive. Of the sleep characteristics evaluated, snoring (51\%) followed by poor sleep continuity (40\%) and delayed sleep onset (34\%) were the most common sleep disturbances. The most commonly reported adverse social exposures were low subjective social status $(71 \%)$, high perceived stress $(60 \%)$, and social isolation $(57 \%)$.

\section{Bivariate analysis}

In bivariate analysis, two of the five sleep characteristics were significant predictors of elevated BP (Table 2). The odds of elevated BP were significantly higher among those who reported the following: (1) snoring or being told that they stopped breathing when asleep $(\mathrm{OR}=1.72,95 \% \mathrm{CI}=1.21-2.45)$ and (2) poor sleep continuity $(\mathrm{OR}=1.53,95 \% \mathrm{CI}=1.03-2.27)$. For adverse social exposures, the odds of elevated BP were significantly higher among those who reported discrimination $(\mathrm{OR}=1.90,95 \% \mathrm{CI}=1.30-2.78)$, but was significantly lower among those who reported child abuse $(\mathrm{OR}=0.56,95 \% \mathrm{CI}=0.38-0.84)$. Next (not shown), we examined type of child abuse (i.e., physical, sexual, and emotional) separately as predictors. The results were mostly consistent with the above results, so subsequent analyses were conducted using the combined abuse variable.

Of the demographics and clinical characteristics, the odds of elevated BP were significantly higher among participants who (1) were older $(\mathrm{OR}=1.14$, 95\% CI = 1.01-1.28); (2) had lower educational levels $(\mathrm{OR}=1.52,95 \% \mathrm{CI}=0.94-2.44)$; (3) had overweight or obesity $(\mathrm{OR}=2.96,95 \% \mathrm{CI}=1.39-6.31)$; and (4) reported poorer self-rated health $(\mathrm{OR}=1.90,95 \%$ $\mathrm{CI}=1.10-3.27)$. None of the health behaviors significantly predicted elevated BP. Thus, age, overweight/ obese, low education, and self-rated health were included as covariates in the multivariable model.

\section{Multivariable analysis}

In the first model (Table 3), poor sleep continuity $(\mathrm{aOR}=1.64,95 \% \mathrm{CI}=1.04-2.60)$, snoring $(\mathrm{aOR}=1.70$, 95\% $\mathrm{CI}=1.13-2.56$ ), and experiencing discrimination $(\mathrm{aOR}=2.15,95 \% \mathrm{CI}=1.38-3.33)$ were significantly associated with higher odds of elevated BP. Social isolation $(\mathrm{aOR}=0.56,95 \% \mathrm{CI}=0.36-0.88)$ and child abuse $(\mathrm{aOR}=0.53,95 \% \mathrm{CI}=0.32-0.86)$ were associated with lower odds of elevated BP. The associations with elevated $\mathrm{BP}$ remained significant in model 2 , but some were no longer significant in the final model.

In the fully adjusted model, the probability of elevated $\mathrm{BP}$ was significantly higher in black women who reported the following: overweight/obesity $(\mathrm{aOR}=3.20$, $95 \% \mathrm{CI}=1.52-6.71$ ), prior diagnosis of hypertension $(\mathrm{aOR}=6.94,95 \% \mathrm{CI}=3.3-14.40)$, poor sleep continuity 
Table 2. Bivariate Relationships Between Predictors and Blood Pressure $(\boldsymbol{N}=\mathbf{5 8 1})$

\begin{tabular}{|c|c|c|c|c|c|c|}
\hline \multirow[b]{2}{*}{ Predictor } & & \multirow{2}{*}{$\begin{array}{l}\text { Elevated BP } \\
\text { Present, } n \text { (\%) }\end{array}$} & \multicolumn{3}{|c|}{ Weighted } & \multirow[b]{2}{*}{$p$} \\
\hline & & & SE & OR & $95 \% \mathrm{Cl}$ & \\
\hline \multicolumn{7}{|l|}{ Demographics } \\
\hline Age (descending) & & - & - & 1.14 & $1.01-1.28$ & 0.033 \\
\hline \multirow[t]{2}{*}{ Low education } & Yes & $44(39.32)$ & 5.26 & 1.52 & $0.94-2.44$ & 0.086 \\
\hline & No (Ref.) & 129 (29.94) & 2.71 & & & \\
\hline \multirow[t]{2}{*}{ Low income } & Yes & $44(33.17)$ & 5.05 & 1.03 & $0.64-1.66$ & 0.916 \\
\hline & No (Ref.) & $115(32.61)$ & 2.85 & & & \\
\hline \multicolumn{7}{|l|}{ Clinical characteristics } \\
\hline \multirow[t]{2}{*}{ Overweight/obese } & Yes & $157(36.84)$ & 2.78 & 2.96 & $1.39-6.31$ & 0.005 \\
\hline & No (Ref.) & $14(16.44)$ & 5.00 & & & \\
\hline \multirow{2}{*}{ Depression symptoms } & Yes & $41(30.19)$ & 4.79 & 0.87 & $0.52-1.47$ & 0.602 \\
\hline & No (Ref.) & $132(3.16)$ & 3.04 & & & \\
\hline \multirow[t]{2}{*}{ Poorer health } & Yes & $37(45.04)$ & 6.22 & 1.90 & $1.10-3.27$ & 0.021 \\
\hline & No (Ref.) & $136(30.13)$ & 2.76 & & & \\
\hline \multicolumn{7}{|l|}{ Health behaviors } \\
\hline \multirow[t]{2}{*}{ Tobacco use } & Yes & 39 (32.08) & 4.36 & 0.98 & $0.59-1.65$ & 0.951 \\
\hline & No (Ref.) & $130(32.43)$ & 3.40 & & & \\
\hline \multirow[t]{2}{*}{ Poor diet } & Yes & $74(32.27)$ & 3.90 & 0.99 & $0.60-1.64$ & 0.965 \\
\hline & No (Ref.) & $98(32.51)$ & 3.75 & & & \\
\hline \multirow[t]{2}{*}{ Physical inactivity } & Yes & $141(31.93)$ & 2.98 & 0.86 & $0.47-1.58$ & 0.624 \\
\hline & No (Ref.) & $32(35.30)$ & 5.99 & & & \\
\hline \multicolumn{7}{|l|}{ Sleep characteristics } \\
\hline \multirow[t]{2}{*}{ Delayed sleep onset } & Yes & $78(40.2)$ & 4.70 & 1.36 & $0.90-2.03$ & 0.142 \\
\hline & No (Ref.) & $126(33.2)$ & 2.41 & & & \\
\hline \multirow[t]{2}{*}{ Poor sleep continuity } & Yes & $93(41.5)$ & 4.23 & 1.53 & $1.03-2.27$ & 0.035 \\
\hline & No (Ref.) & $111(31.6)$ & 2.67 & & & \\
\hline \multirow[t]{2}{*}{ Snoring } & Yes & $118(41.7)$ & 3.27 & 1.72 & $1.21-2.45$ & 0.003 \\
\hline & No (Ref.) & $85(29.3)$ & 3.12 & & & \\
\hline \multirow[t]{2}{*}{ Short sleep } & Yes & $29(47.8)$ & 7.56 & 1.74 & $0.92-3.31$ & 0.090 \\
\hline & No (Ref.) & $177(34.5)$ & 2.56 & & & \\
\hline \multirow[t]{2}{*}{ Long sleep } & Yes & $24(37.9)$ & 8.30 & 1.10 & $0.52-2.34$ & 0.809 \\
\hline & No (Ref.) & $182(35.7)$ & 2.70 & & & \\
\hline \multicolumn{7}{|l|}{ Social exposures } \\
\hline \multirow[t]{2}{*}{ Social isolation } & Yes & $111(33.1)$ & 3.05 & 0.76 & $0.55-1.06$ & 0.103 \\
\hline & No (Ref.) & $95(39.4)$ & 3.21 & & & \\
\hline \multirow[t]{2}{*}{ Discrimination } & Yes & $75(46.2)$ & 4.09 & 1.90 & $1.30-2.78$ & 0.001 \\
\hline & No (Ref.) & $131(31.1)$ & 2.86 & & & \\
\hline High perceived stress & Yes & $120(34.2)$ & 3.01 & 0.84 & $0.55-1.28$ & 0.417 \\
\hline & No (Ref.) & $86(38.2)$ & 4.05 & & & \\
\hline Low subjective social status & Yes & $151(36.9)$ & 3.09 & 1.17 & $0.70-1.95$ & 0.542 \\
\hline & No (Ref.) & $54(33.3)$ & 4.76 & & & \\
\hline Child abuse & Yes & $58(27.4)$ & 3.71 & 0.56 & $0.38-0.84$ & 0.006 \\
\hline & No & $143(40.1)$ & 3.00 & & & \\
\hline
\end{tabular}

Bold indicates $p<0.05$.

All models are adjusted for the complex sampling design.

$\mathrm{Cl}$, confidence interval; HTN, hypertension; OR, odds ratio.

$(\mathrm{aOR}=1.70,95 \% \mathrm{CI}=1.07-2.70)$, and discrimination $(\mathrm{aOR}=1.61,95 \% \mathrm{CI}=1.00-2.58)$. Interestingly, the adjusted odds of elevated BP remained significantly lower among those who reported more social isolation $(\mathrm{aOR}=0.69,95 \% \mathrm{CI}=0.48-0.99)$.

\section{Discussion}

We examined the association of adverse social experiences and sleep characteristics with hypertension among young adult black females, an age and sex demographic at high risk for hypertension. Our novel findings identified discrimination and poor sleep continuity as significant risk factors for elevated BP among this subgroup of women, highlighting the importance of assessing for a broad range of risk factors beyond the traditional diet and physical activity behaviors. This study is among the few to use population representative data and objective $\mathrm{BP}$ data to examine sleep 
Table 3. Relationship Between Sleep, Social Adversity, and Blood Pressure $(N=581)$

\begin{tabular}{|c|c|c|c|c|c|c|}
\hline \multirow[b]{2}{*}{ Domain } & \multicolumn{2}{|c|}{ Model 1} & \multicolumn{2}{|c|}{ Model 2} & \multicolumn{2}{|c|}{ Model 3} \\
\hline & $\mathrm{aOR}$ & $95 \% \mathrm{Cl}$ & $\mathrm{aOR}$ & $95 \% \mathrm{Cl}$ & aOR & $95 \% \mathrm{Cl}$ \\
\hline \multicolumn{7}{|l|}{ Sleep characteristics } \\
\hline Delayed sleep onset & 1.16 & $0.74-1.83$ & 1.17 & $0.70-1.94$ & 1.09 & $0.62-1.92$ \\
\hline Poor sleep continuity & 1.64 & $1.04-2.60$ & 1.86 & $1.16-2.98$ & 1.70 & $1.07-2.70$ \\
\hline Snoring & 1.70 & $1.13-2.56$ & 1.51 & $1.01-2.24$ & 1.43 & $1.01-2.04$ \\
\hline Short sleep & 1.06 & $0.48-2.33$ & 0.79 & $0.38-1.64$ & 1.28 & $0.62-2.66$ \\
\hline Long sleep & 1.45 & $0.71-2.95$ & 1.38 & $0.66-2.89$ & 1.39 & $0.55-3.50$ \\
\hline \multicolumn{7}{|l|}{ Social adversity } \\
\hline Social isolation & 0.56 & $0.36-0.88$ & 0.60 & $0.38-0.95$ & 0.69 & $0.48-0.99$ \\
\hline Discrimination & 2.15 & $1.38-3.33$ & 1.79 & $1.09-2.95$ & 1.61 & $1.00-2.58$ \\
\hline High perceived stress & 0.65 & $0.38-1.11$ & 0.68 & $0.39-1.17$ & 0.66 & $0.38-1.16$ \\
\hline Low subjective social status & 1.18 & $0.66-2.09$ & 1.18 & $0.66-2.09$ & 1.15 & $0.68-1.95$ \\
\hline Child abuse & 0.53 & $0.32-0.86$ & 0.55 & $0.33-0.93$ & 0.53 & $0.33-0.87$ \\
\hline \multicolumn{7}{|l|}{ Demographics } \\
\hline Age (descending) & & & 1.13 & $0.97-1.30$ & 1.04 & $0.90-1.20$ \\
\hline Low education & & & 1.35 & $0.75-2.42$ & 1.50 & $0.79-2.88$ \\
\hline \multicolumn{7}{|l|}{ Clinical characteristics } \\
\hline Overweight/obese & & & 3.25 & $1.54-6.88$ & 3.20 & $1.52-6.71$ \\
\hline Poorer health & & & 1.31 & $0.71-2.41$ & 0.94 & $0.44-2.02$ \\
\hline \multicolumn{7}{|l|}{ Medical history } \\
\hline Hypertension & & & & & 6.94 & $3.35-14.40$ \\
\hline Diabetes & & & & & 0.74 & $0.18-3.00$ \\
\hline Hyperlipidemia & & & & & 0.47 & $0.13-1.69$ \\
\hline Heart disease & & & & & 1.59 & $0.29-8.84$ \\
\hline
\end{tabular}

Bold $\mathrm{aOR}=p<0.05$.

All models are adjusted for the complex sampling design.

aOR, adjusted odds ratio; Model 1, adjusted for other sleep characteristics and social adversity variables; Model 2, adjusted demographics and clinical characteristics; Model 3, adjusted for past medical history.

and the social environment as risk factors for young black women to develop hypertension.

Poor sleep continuity, assessed as frequent awakening, was the only sleep characteristic that was significantly associated with BP after adjusting for other factors that influence the development of hypertension. There are many possible causes of poor sleep continuity. We examined two possibilities, snoring, which may be related to sleep apnea, and depression, and neither was significantly associated with hypertension in this sample. However, we did not measure anxiety, which is also associated with both sleep and hypertension. ${ }^{31,32}$ Future research should attempt to replicate our findings, as well as explore other individual and family factors that may contribute to poor sleep continuity. Possibilities include frequent awakening related to a bed partner's snoring, ${ }^{33}$ caregiving of young children, loneliness, ${ }^{34}$ stress, $^{32}$ and traumatic experiences (e.g., nightmares). ${ }^{35}$ Racism and discrimination are examples of chronic stressful experiences, which could impair sleep through rumination ${ }^{36,37}$ and perceived stress, ${ }^{38,39}$ but future work should explore these mechanisms further.

Women who reported experiencing discrimination had almost double the odds of hypertension compared to young women who did not report discrimination. This relationship was only partially attenuated when we controlled for other factors influencing hypertension. Our findings are somewhat consistent with other studies examining the association of discrimination and BP, although few studies have examined this relationship in young adults. A study of 30,000 black women with a median age of 37 years found a positive association between discrimination and hypertension only for women born outside of the United States and those who grew up in predominantly white communities. ${ }^{40}$ Krieger and Sidney ${ }^{10}$ examined the relationship of discrimination and BP in a similar sample of young adults. They found that BP was higher in working class black women who reported no discriminatory experiences, or a passive coping style, such as keeping such experiences to themselves. ${ }^{10}$ Future research should explore the experiences of young adults related to unfair treatment, ways of coping, and potential CV consequences of both discrimination and behavioral responses to discrimination. Clinicians and researchers should also be aware of the impact of social adversities on health to advocate for communities at the macro level and to develop interventions that support positive health behaviors in the face of adversity. 
A surprising finding was the inverse association of social isolation with elevated BP. Stated plainly, more social isolation was associated with lower BP. At first examination, this relationship seems counterintuitive, given studies that suggest social support buffers against stress. However, the wear and tear from the expectations that come with family and social relationships may take a toll on CVH. In fact, the negative health consequences of caregiving are well documented in the literature. ${ }^{41,42}$ Caregiving occurs in the context of raising a family, as is common for the developmental stage of young adulthood, plus some black women have been caregiving since childhood due to phenomena like grandparents raising children, and heart disease and strokes affecting black families at earlier ages. ${ }^{42}$ Consequently, for some black women, the internalization of the "Strong Black Woman" ideology includes a relentless obligation to care for others, sometimes to the detriment of their own health. ${ }^{43,44}$ Understanding how social networks and family life affect young black women is a critical future area for study. Researchers must begin to untangle the nuanced ways that social and family connections, and the expectations that come with them, may serve as protective factors or may impose risk.

\section{Limitations}

This study is among the few to focus on BP in young adult black women, but the cross-sectional design is a significant limitation. A second limitation is the measurement of social adversity factors (e.g., discrimination) using single-item questions; however, all items are from validated instruments. Our findings are useful for identifying areas of focus in future research tailored to address health inequities experienced by young black women.

As this study is a secondary analysis of publicly available data from a large, multistate study, we are limited to the data that are available. Consequently, we were not able to adjust for medication use, but we did adjust for the most common indications for the use of antihypertensive medications. The existing data also do not include prior diagnosis of obstructive sleep apnea, which is a risk factor for hypertension and associated with several of the sleep characteristics examined in this study. ${ }^{1,15}$ Nevertheless, after covarying for CV comorbidities associated with obstructive sleep apnea, poor sleep continuity remained a significant predictor of elevated BP. The findings from this study are a significant contribution to the literature, given the objective measurement of the outcome variable, $\mathrm{BP}$, the population representativeness of our sample, and the inclusion of behaviors and determinants that have not been as well studied in this group of women.

Our assessment of child abuse is a retrospective account, as are most published studies of the CVH consequences of child abuse. However, previous investigations have determined that retrospective reports of child maltreatment are reliable and may be conservative estimates. ${ }^{45,46}$ Finally, all self-reported data are subject to bias, including our measurement of sleep behaviors. Future research should continue to explore BP and sleep behaviors in young black women utilizing objective sleep data, such as polysomnography.

\section{Conclusion}

Adverse social exposures and poor sleep continuity are understudied as risk factors for hypertension in young black females. Based on our findings, risk assessments for this group of women should include questions about social network burden and experiences of discrimination. Collaborative models with communitybased behavioral health care providers could facilitate young women receiving the mental health support needed to manage the stress related to social adversities. However, discrimination and other social adversity stem from inequities in the community and society at large; thus, multilevel approaches at the local, community, and national levels are needed.

\section{Author Disclosure Statement}

No competing financial interests exist.

\section{Funding Information}

This research is funded, in part, by the Robert Wood Johnson Foundation Future of Nursing Scholars program. The writing of this article is funded, in part, by the National Institute of Nursing Research, Grant No. 1F31-NR018579-01. The views expressed here do not necessarily reflect the views of the funding agencies.

\footnotetext{
References

1. Benjamin EJ, Blaha MJ, Chiuve SE, et al. Heart disease and stroke statistics2017 update: a report from the American Heart Association. Circulation. 2017;135:e146-e603.

2. Fryar CD, Ostchega $Y$, Hales $C M$, et al. Hypertension prevalence and control among Adults: United States, 2015-2016. NCHS Data Brief. 2017; 289:1-8.

3. Thomas SJ, Booth III JN, Dai C, et al. Cumulative incidence of hypertension by 55 years of age in blacks and whites: the CARDIA Study. J Am Heart Assoc. 2018;7:e007988.

4. Sparrenberger F, Cichelero FT, Ascoli AM, et al. Does psychosocial stress cause hypertension? A systematic review of observational studies. J Hum Hypertens. 2009;23:12-19.
} 
5. Sonu S, Post S, Feinglass J. Adverse childhood experiences and the onset of chronic disease in young adulthood. Prev Med. 2019;123:163-170.

6. Felitti VJ, Anda RF, Nordenberg D, et al. Relationship of childhood abuse and household dysfunction to many of the leading causes of death in adults. The Adverse Childhood Experiences (ACE) Study. Am J Prev Med. 1998;14:245-258.

7. Holt-Lunstad J, Smith TB, Layton JB. Social relationships and mortality risk: a meta-analytic review. PLoS Med. 2010;7:e1000316.

8. Pantell $M$, Rehkopf $D$, Jutte $D$, et al. Social isolation: a predictor of mortality comparable to traditional clinical risk factors. Am J Public Health. 2013;103:2056-2062.

9. Slopen N, Lewis TT, Williams DR. Discrimination and sleep: a systematic review. Sleep Med. 2016;18:88-95.

10. Krieger N, Sidney S. Racial discrimination and blood pressure: the CARDIA Study of young black and white adults. Am J Public Health. 1996;86:1370 1378.

11. Williams DR, Yu Y, Jackson JS, Anderson NB. Racial differences in physical and mental health: socio-economic status, stress and discrimination. J Health Psychol. 1997;2:335-351.

12. Cundiff JM, Matthews KA. Is subjective social status a unique correlate of physical health? A meta-analysis. Health Psychol. 2017;36:1109-1125.

13. Adler N, Singh-Manoux A, Schwartz J, et al. Social status and health: a comparison of British civil servants in Whitehall-Il with European-and African-Americans in CARDIA. Soc Sci Med. 2008;66:1034-1045.

14. Sims M, Diez-Roux AV, Dudley A, et al. Perceived discrimination and hypertension among African Americans in the Jackson Heart Study. Am J Public Health. 2012;102(S2):S258-S265.

15. Jackson $C L$, Redline $S$, Emmons $K M$. Sleep as a potential fundamental contributor to disparities in cardiovascular health. Ann Rev Public Health. 2015;36:417-440.

16. Walsemann KM, Ailshire JA, Fisk $C E$, et al. Do gender and racial/ethnic disparities in sleep duration emerge in early adulthood? Evidence from a longitudinal study of U.S. adults. Sleep Med. 2017;36:133-140.

17. Ford CL, Airhihenbuwa CO. Critical Race Theory, race equity, and public health: toward antiracism praxis. Am J Public Health. 2010;100(Suppl. 1): S30-S35.

18. Geronimus AT, Hicken M, Keene D, Bound J. "Weathering" and age patterns of allostatic load scores among blacks and whites in the United States. Am J Public Health. 2006;96:826-833.

19. Geronimus AT, Bound J, Keene D, Hicken M. Black-white differences in age trajectories of hypertension prevalence among adult women and men, 1999-2002. Ethn Dis. 2007;17:40-48.

20. Mullan-Harris K. 2013. The Add Health Study: Design and accomplishments. Available at www.cpc.unc.edu/projects/addhealth/ documentation/guides/DesignPaperWave_IIV.pdf Accessed July 1, 2019.

21. Bratter JL, Gorman BK. Does multiracial matter? A study of racial disparities in self-rated health. Demography. 2011;48:127-152.

22. Wenger NK, Arnold A, Bairey Merz CN, et al. Hypertension across a woman's life cycle. J Am Coll Cardiol. 2018;71:1797-1813.

23. Entzel P, Whitsel EA, Richardson A, et al. 2009. Add Health wave IV documentation: cardiovascular and anthropometric measures. Available at www.cpc.unc.edu/projects/addhealth/documentation/guides/Wave_IV_ cardiovascular_and_anthropometric_documentation_111909_revised .pdf Accessed September 1, 2019.

24. Egan BM. Defining hypertension by blood pressure $130 / 80 \mathrm{~mm} \mathrm{Hg}$ leads to an impressive burden of hypertension in young and middle-aged black adults: follow-up in the CARDIA study. J Am Heart Assoc. 2018;7:e009971.

25. Radloff LS. The CES-D scale: a self-report depression scale for research in the general population. Appl Psychol Meas. 1977;1:385-401.

26. Canady RB, Stommel M, Holzman C. Measurement properties of the centers for epidemiological studies depression scale (CES-D) in a sample of African American and non-Hispanic White pregnant women. J Nurs Meas. 2009;17:91-104.

27. Hays RD, Spritzer KL, Thompson WW, Cella D. US general population estimate for "excellent" to "poor" self-rated health item. J General Intern Med. 2015;30:1511-1516.

28. Cohen S, Kamarck T, Mermelstein R. A global measure of perceived stress. J Health Soc Behav. 1983;24:385-396.

29. Bahadoran Z, Mirmiran P, Azizi F. Fast food pattern and cardiometabolic disorders: a review of current studies. Health Promotion Perspectives. 2015;5:231.
30. Streiner DL, Norman GR. Correction for multiple testing: is there a resolution? Chest. 2011;140:16-18.

31. Jonas BS, Franks $P$, Ingram DD. Are symptoms of anxiety and depression risk factors for hypertension? Longitudinal evidence from the National Health and Nutrition Examination Survey I Epidemiologic Follow-up Study. Arch Fam Med. 1997;6:43-49.

32. Staner L. Sleep and anxiety disorders. Dialog Clin Neurosci. 2003;5:249.

33. Beninati W, Harris CD, Herold DL, Shepard JW. The effect of snoring and obstructive sleep apnea on the sleep quality of bed partners. Mayo Clin Proc. 1999;74:955-958.

34. Kurina LM, Knutson KL, Hawkley LC, et al. Loneliness is associated with sleep fragmentation in a communal society. Sleep. 2011;34:1519-1526.

35. Lind MJ, Baylor A, Overstreet CM, et al. Relationships between potentially traumatic events, sleep disturbances, and symptoms of PTSD and alcohol use disorder in a young adult sample. Sleep Med. 2017;34:141-147.

36. Lewis T, Troxel WM, Kravitz HM, et al. Chronic exposure to everyday discrimination and sleep in a multiethnic sample of middle-aged women. Health Psychol. 2013;32:810-819.

37. Hoggard LS, Hill LK. Examining how racial discrimination impacts sleep quality in African Americans: is perseveration the answer? Behav Sleep Med. 2018;16:471-481.

38. Johnson DA, Lisabeth $L$, Lewis $\Pi$, et al. The contribution of psychosocial stressors to sleep among African Americans in the Jackson Heart Study. Sleep. 2016;39:1411-1419.

39. Majeno A, Tsai KM, Huynh VW, et al. Discrimination and sleep difficulties during adolescence: the mediating roles of loneliness and perceived stress. J Youth Adolesc. 2018:47:135-147.

40. Cozier Y, Palmer JR, Horton NJ, et al. Racial discrimination and the incidence of hypertension in US black women. Ann Epidemiol. 2006;16: 681-687.

41. Chiang JJ, Tsai KM, Park $H$, et al. Daily family stress and HPA axis functioning during adolescence: the moderating role of sleep. Psychoneuroendocrinology. 2016;71:43-53.

42. Siskowski C. Young caregivers: effect of family health situations on school performance. J School Nurs. 2006;22:163-169.

43. Nelson T, Cardemil EV, Adeoye CT. Rethinking strength: black women's perceptions of the "Strong Black Woman" role. Psychol Women Q. 2016; 40:551-563.

44. Woods-Giscombe CL. Superwoman schema: African American women's views on stress, strength, and health. Qual Health Res. 2010;20:668-683.

45. Edwards VJ, Anda RF, Nordenberg DF, et al. Bias assessment for child abuse survey: factors affecting probability of response to a survey about childhood abuse. Child Abuse Negl. 2001;25:307-312.

46. Reuben A, Moffitt TE, Caspi A, et al. Lest we forget: comparing retrospective and prospective assessments of adverse childhood experiences in the prediction of adult health. J Child Psychol Psychiatry. 2016;57: 1103-1112.

Cite this article as: Scott J, Silva S, Simmons LA (2020) Social adversity, sleep characteristics and elevated blood pressure among young adult black females, Health Equity 4:1, 421-429, DOI: 10.1089/ heq.2020.0033. 